\title{
Comparative venomic profiles of three spiders of the genus Phoneutria
}

\author{
Frederico Francisco Fernandes ${ }^{1,3}$, Juliana Rodrigues Moraes ${ }^{1}$, Jaqueline Leal dos Santos ${ }^{1}$, Thiago Geraldo Soares ${ }^{1}$, \\ Vitor José Pinto Gouveia ${ }^{1}$, Alessandra C. S. Matavel ${ }^{2}$, William de Castro Borges ${ }^{3}$, Marta do Nascimento Cordeiro ${ }^{1}$, \\ Suely Gomes Figueiredo ${ }^{4}$, Márcia Helena Borges ${ }^{1 *}$ (D) \\ ${ }^{1}$ Laboratory of Proteomics and Arachnids, Research and Development Board, Ezequiel Dias Foundation, Belo Horizonte, MG, Brazil. \\ ${ }^{2}$ Laboratory of Biotechnology and Health, Research and Development Board, Ezequiel Dias Foundation, Belo Horizonte, MG, Brazil. \\ ${ }^{3}$ Laboratory of Enzymology and Proteomics, Department of Biological Sciences, Federal University of Ouro Preto, Ouro Preto, MG, Brazil. \\ ${ }^{4}$ Laboratory of Protein Chemistry, Department of Physiological Sciences, Federal University of Espírito Santo, Vitória, ES, Brazil.
}

\section{Keywords:}

Spider venom

Phoneutria

Protein profile

Toxins

Ion channels

\begin{abstract}
Background: Spider venoms induce different physio-pharmacological effects by binding with high affinity on molecular targets, therefore being of biotechnological interest. Some of these toxins, acting on different types of ion channels, have been identified in the venom of spiders of the genus Phoneutria, mainly from $P$. nigriventer. In spite of the pharmaceutical potential demonstrated by $P$. nigriventer toxins, there is limited information on molecules from venoms of the same genus, as their toxins remain poorly characterized. Understanding this diversity and clarifying the differences in the mechanisms of action of spider toxins is of great importance for establishing their true biotechnological potential. This prompted us to compare three different venoms of the Phoneutria genus: $P$. nigriventer $(\mathrm{Pn}-\mathrm{V})$, P. eickstedtae $(\mathrm{Pe}-\mathrm{V})$ and $P$. pertyi $(\mathrm{Pp}-\mathrm{V})$. Methods: Biochemical and functional comparison of the venoms were carried out by SDS-PAGE, HPLC, mass spectrometry, enzymatic activities and electrophysiological assays (whole-cell patch clamp).

Results: The employed approach revealed that all three venoms had an overall similarity in their components, with only minor differences. The presence of a high number of similar proteins was evident, particularly toxins in the mass range of $\sim 6.0 \mathrm{kDa}$. Hyaluronidase and proteolytic activities were detected in all venoms, in addition to isoforms of the toxins Tx1 and Tx2-6. All Tx1 isoforms blocked Nav1.6 ion currents, with slight differences.

Conclusion: Our findings showed that $\mathrm{Pn}-\mathrm{V}, \mathrm{Pe}-\mathrm{V}$ and $\mathrm{Pp}-\mathrm{V}$ are highly similar concerning protein composition and enzymatic activities, containing isoforms of the same toxins sharing high sequence homology, with minor modifications. However, these structural and functional variations are very important for venom diversity. In addition, our findings will contribute to the comprehension of the molecular diversity of the venoms of the other species from Phoneutria genus, exposing their biotechnological potential as a source for searching for new active molecules.
\end{abstract}

* Correspondence: mhborgesb@gmail.com https://doi.org/10.1590/1678-9199-JVATITD-2021-0042 Received: 05 April 2021; Accepted: 20 July 2021; Published online: 09 February 2022 


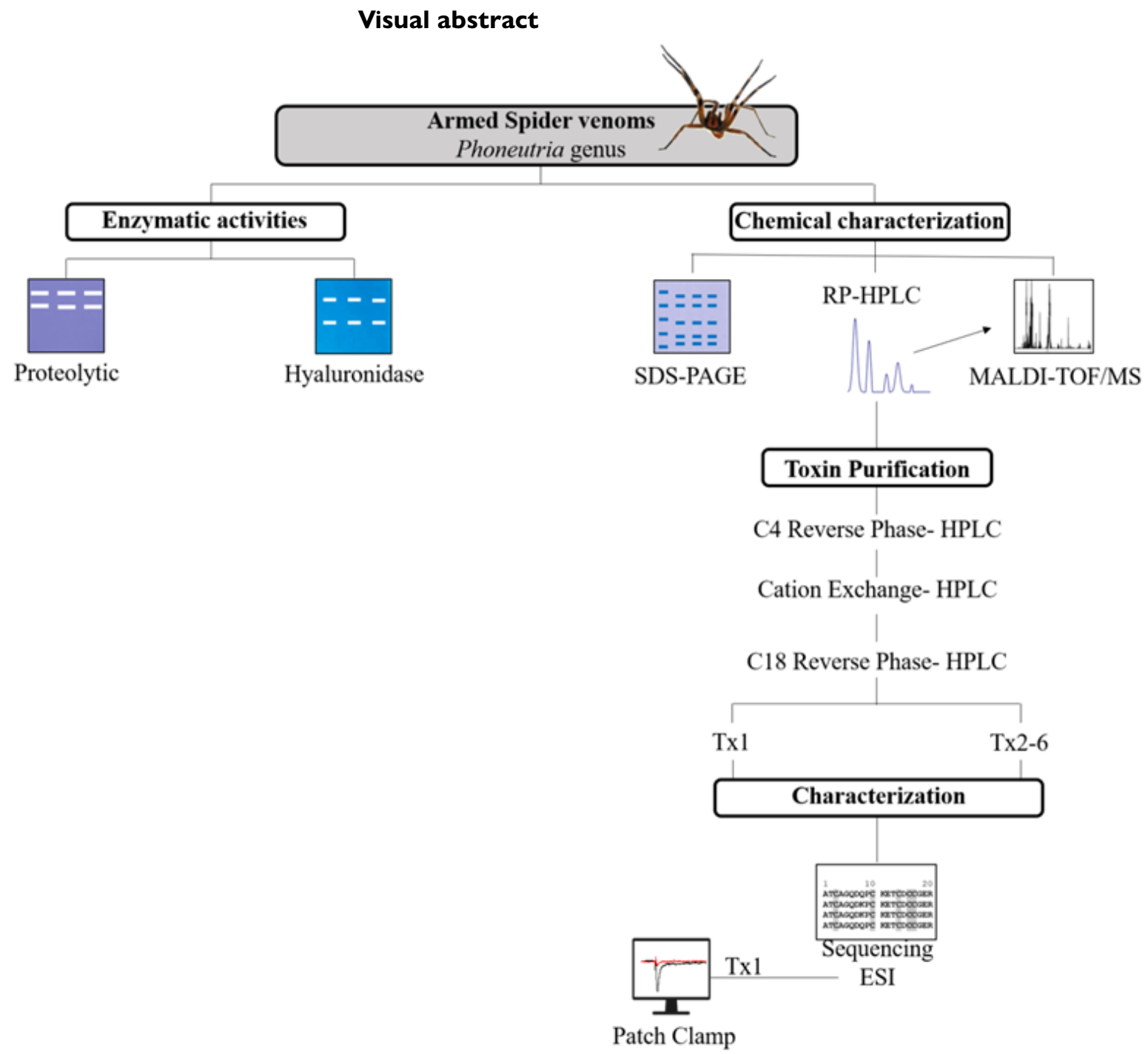

\section{Background}

Among the components of spider venoms, a wide variety of toxins evolved to bind to specific targets of biological importance, such as ion channels, inducing biological effects that allow spiders to immobilize their prey in a very efficient way, using minor quantities of their toxins [1,2]. These venoms contributed to the enormous evolutionary success of spiders, providing the basis for their highly abundance on the planet. Spider venoms are being used for the discovery and development of new biologically active molecules for medical and biotechnological purposes, drug design, and application in agriculture or as pharmacological tools [3-8]. It is likely that many other applications will be discovered, because despite the large number of species already described, there is relatively limited knowledge concerning the composition of spider venoms.

The first studies on spider venoms started in the middle of the $20^{\text {th }}$ century and have advanced enormously up to the present time, suggesting the immeasurable biotechnological potential of these molecules [9]. In a recent review, Muttenthaler et al. [10] described that venom-derived peptides are also being used to drug development for the treatment of diseases, and they are providing templates for engineering of novel diagnostic agents and therapeutics.

Besides, the advances in high throughput methods, such as transcriptomics, and the use of mass spectrometry-based, large-scale proteomics allowed a faster identification and characterization of new molecules, with a minimum amount of the samples [11-13]. The findings have revealed the diversity of the venoms and are uncovering their biotechnological potential.

In Brazil, "Brazilian wandering spiders" or "banana-spiders" species of the genus Phoneutria Perty, 1833, are amongst the most explored and studied spider venoms, in particular Phoneutria nigriventer. Phoneutria sp. are synanthropic species and, therefore, they are responsible for the high number of human accidents caused by these arthropods. These accidents occur mainly in Brazil, but there are reports of cases in Central America and other nearby countries [14]. 
Species from the genus Phoneutria, family Ctenidae, suborder Araneomorphae, inhabit forests from Central America, South America, East of the Andes and North of Argentina. In Brazil, $P$. nigriventer, P. keyserlingi, P. pertyi, P. bahiensis and P. eickstedtae species are found in Atlantic Rainforest and forest fragments in the Cerrado. P. nigriventer species are the most widely distributed in Brazil, being found in the states of Minas Gerais, Goiás, Mato Grosso do Sul, Espírito Santo, Rio de Janeiro, São Paulo, Paraná, Santa Catarina and Rio Grande do Sul. P. pertyi species inhabit Atlantic rainforests, from the southeast of Bahia state, eastern parts of Minas Gerais, Espírito Santo and northwestern of Rio de Janeiro. P. eickstedtae species are found in fragments of Atlantic Rainforest in the Cerrado of Tocantins states, Goiás, Mato Grosso and Mato Grosso do Sul [15].

Studies on $P$. nigriventer venom have been reported since the 1950s. They have shown the venom to be composed of molecules with diverse biological activities responsible for the envenomation effects $[6,16,17]$. P. nigriventer is one of the few spiders of medical relevance in the world, being responsible for the majority of human accidents with spiders, most of them in Brazil [18]. The accidents - referred to as phoneutrism - are characterized by local and systemic effects that include intense pain, edema, convulsions, agitation, nausea, lachrymation, excessive salivation, tremors, spastic paralysis, neurotoxicity, hypertension, cardiac arrhythmia, and penile erection (priapism) [18-20]. These effects are induced by a complex mixture of neurotoxins, short chain peptides (up to $2 \mathrm{kDa}$ ) and enzymes (such as hyaluronidase and peptidases) [21].

In previous studies, our research group purified and characterized four distinct families of neurotoxins from $P$. nigriventer venom, referred to as Phoneutria toxins (PhTxl, $\mathrm{PhTx} 2, \mathrm{PhTx} 3$ and PhTx4) [22]. PhTx refers to the fractions that encompass toxins, while the numbers $(1,2,3$ or 4$)$ are derived from the first step of purification procedure. On the other hand, PnTx (for example PnTx1 or PnTx2-6) is the denomination of isolated toxins (peptides) from each specific fraction (for a review, see $[17,21,22])$.

These are polypeptides with different primary structures (3080 amino acid residues in length, MW 3.5-9.0 kDa) displaying different pharmacological properties [21]. These toxins comprise most of the venom compounds and interact with neuronal ion channels, modulating their activity, and with chemical receptors of the neuromuscular systems of mammals and insects, affecting neurotransmitter release [23]. Considering the ability of Phoneutria toxins to bind to ion channels, and the role these channels play in different types of biological events, including in some diseases (channelopathies), the biochemical characterization of its components is of major relevance. Previous investigations were focused on the biotechnological potential of these toxins [24], as models of therapeutic molecules [6], for cell permeability studies $[25,26]$, or for the development of drugs that pass the blood-brain barrier [26-28].
Some Phoneutria toxins have been widely explored. Apart from the family PhTxl, from which only one toxin was identified (initially termed "Tx1" and lately PnTx1), the other families $\mathrm{PhTx} 2, \mathrm{PhTx} 3$ and PhTx 4 - have been described as collections of isotoxins (named PnTx2, PnTx3 and PnTx4) that share sequences with high identity and similar patterns, e.g., disulfide bridges, in addition to some particular features [6,17,21,29-31].

PnTx1 and its recombinant toxin (rPnTx1) inhibit different subtypes of voltage-dependent sodium channels (Nav), but not the cardiac isoform Nav1.5 [32,33]. These toxins have a particular high affinity for the neuronal isoform Navl.2. Both PnTx1 and rPnTx1 are promising for the development of new drugs, considering the reports on their specificity and selectivity.

$\mathrm{PhTx} 2$ toxins inhibit sodium channel inactivation. These toxins are the main responsible for the strongest neurotoxic effects of venom $[17,18,23,34]$. Two of them - PnTx2-5 and PnTx26 toxins - are responsible for the penile erection observed in the envenomation caused by Phoneutria [29], an effect associated with the nitric oxide (NO)/cyclic GMP pathway. These toxins have been explored as models for the development of a potential drug for the treatment of erectile dysfunction [34-36].

The PhTx 3 family contains the most heterogeneous toxins. This group includes PnTx3-1, a blocker of inactivating potassium channels currents associated with $\mathrm{Ca}^{2+}$ oscillations and pacemaker activity [37]. In contrast, the other toxins of this family (PnTx3-2, PnTx3-3, PnTx3-4, PnTx3-5 and PnTx3-6) block voltage-gated calcium channels with different activities/affinities [38,39]. PnTx33 and PnTx3-4 inhibit calcium influx [40], exocytosis, and glutamate release in synaptosomes [41,42]. Besides, it has been shown that PnTx3-6 and Tx3-5 can induce analgesic effects and are efficient in the treatment of persistent pathological pain [43-47].

$\mathrm{PhTx} 4$ family of $P$. nigriventer neurotoxins, comprises toxins with insecticidal activities that modulate insect sodium channels $[31,48,49]$. Despite this apparent lack of toxicity to mammals, PnTx4(5-5) was shown to inhibit NMDA ionotropic glutamate receptors in rat brain neurons [50]. Like PnTx(3-6 and 3-5), PnTx4(5-5) and PnTx4(6-1) showed analgesic effects in different pain models [51,52].

Using transcriptomic and proteomic approaches Diniz et al. [53] revealed the presence of novel compounds in P. nigriventer venom. It was found that cysteine-rich peptide toxins are the most abundant components displaying a conserved disulfide scaffold. Other components are proteinase inhibitors, metalloproteinases and hyaluronidases [53]. All these studies have shown that $P$. nigriventer venom has been intensively investigated for drug discovery and their toxins have shown a great biotechnological potential associated with their biochemical and pharmacological properties, but only few studies have focused on the insecticidal properties of the venom components [49]. Since the Phoneutria venom is not completely explored, the study of this venom has gained considerable interest and prominence in the scientific community. However, the venoms of other Phoneutria species remain poorly investigated. 
Paiva et al. [54] carried out the transcriptomic analysis of the spider Phoneutria pertyi venom glands and revealed a high similarity to toxins described for the Phoneutria genus. In order to gain further information on venoms of other species from the Phoneutria genus and assess their biotechnological potential, in this work, we conducted a comparative study on the venoms of P. nigriventer, P. eickstedtae and P. pertyi.

\section{Methods}

\section{Animals and venoms}

$P$. nigriventer $(\mathrm{Pn})$ and $P$. pertyi $(\mathrm{Pp})$ specimens were collected in Minas Gerais State (MG), and P. eickstedtae (Pe) in Goiás State, Brazil. The collection was carried out according to the national license for collection provided by the Brazilian Biodiversity Information and Authorization System (SISBIO 21102-7 20152016), whereas the obtained License for Access to Genetic Patrimony (Sisgen A55CA3C) provides access to genetic heritage for conservation and sustainable use of biodiversity.

Spiders were kept in the Scientific Arachnidarium at Ezequiel Dias Foundation (MG) and the venoms obtained by electrical stimulation of fangs, as described by Barrio and Vital Brazil [55], with modifications [21]. Venoms were homogenized in ultrapure water at $4{ }^{\circ} \mathrm{C}$, centrifuged (20 min; at 20,000 x g; at $4{ }^{\circ} \mathrm{C}$ ) and the supernatants collected, lyophilized, and stored at $-20^{\circ} \mathrm{C}$. Venom samples were labeled according to species, as $\mathrm{Pn}-\mathrm{V}, \mathrm{Pp}-\mathrm{V}$ and $\mathrm{Pe}-\mathrm{V}$. The protein concentration was determined by the BCA method developed by Smith et al. [56].

\section{Enzymatic assays}

Zymography

Gelatinolytic and hyaluronidase activities were assayed by zymography. Phoneutria venoms samples $(50 \mu \mathrm{g})$ were subjected to SDS-PAGE in $12.5 \%$ gels containing either $0.1 \%$ gelatin or $1.5 \%$ hyaluronic acid copolymerized under non-reducing conditions, according to Heussen and Dowdle [57] and Gouveia et al. [58]. After electrophoresis, the gels were washed in $2.5 \%$ (v/v) Triton $\mathrm{X}-100$ solution for $1 \mathrm{~h}$ to remove SDS and rinsed in water to remove Triton $\mathrm{X}-100$.

For the gelatinolytic activity assay, gels were incubated in 0.2 $\mathrm{M}$ phosphate buffer, $\mathrm{pH} 8.0$, at $37^{\circ} \mathrm{C}$ for 40 min and stained with Coomassie blue R-250. For the hyaluronidase activity assay, the gels were incubated in $0.2 \mathrm{M}$ phosphate buffer, $\mathrm{pH} 6.0$, at $37^{\circ} \mathrm{C}$ for $120 \mathrm{~min}$, washed with water and kept for $30 \mathrm{~min}$ in $12.5 \%$ $(\mathrm{v} / \mathrm{v})$ trichloroacetic acid at $37^{\circ} \mathrm{C}$. The gels were then washed six times with $3 \%(\mathrm{v} / \mathrm{v})$ acetic acid solution and incubated in the dark with $1 \%(\mathrm{w} / \mathrm{v})$ periodic acid for $1 \mathrm{~h}$ at $25^{\circ} \mathrm{C}$. Next, the gels were rinsed with water and kept in $0.5 \%(\mathrm{w} / \mathrm{v})$ potassium metabisulfite for $30 \mathrm{~min}$ at $25^{\circ} \mathrm{C}$. Finally, the gels were washed with water and stained with $0.5 \%(\mathrm{v} / \mathrm{v})$ Alcian Blue for $4 \mathrm{~h}$. Gelatinolytic and hyaluronidase activities were revealed by colorless bands in the gels.

\section{Colorimetric and turbidimetric assays}

Proteolytic activity of the venoms was quantified using dimethylcasein (DC) as substrate, according to Lin et al. [59] with adaptations. Assays were carried out in PBS buffer, $\mathrm{pH} 8.5$ and $50 \mu \mathrm{L}$ of DC $0.2 \%$ in a final volume of $100 \mu \mathrm{L}$. The reactions were initiated by the addition of $5 \mu \mathrm{g}$ of crude venom, followed by incubation at $37^{\circ} \mathrm{C}$ for $30 \mathrm{~min}$, and stopped by boiling in a water bath ( $3 \mathrm{~min}$ ). Subsequently, $50 \mu \mathrm{L}$ trinitrobenzenesulfonic acid (TNBS) $(0.1 \%)$ and $50 \mu \mathrm{L}$ sodium bicarbonate buffer $(4 \%)$ were added and the mixture kept at $50{ }^{\circ} \mathrm{C}$ for $30 \mathrm{~min}$. Next, $50 \mu \mathrm{L}$ SDS (10\%) and $25 \mu \mathrm{L} 1 \mathrm{M} \mathrm{HCl}$ were added to the mixture. The quantification of hydrolyzed substrate was determined by absorbance at $340 \mathrm{~nm}$. Proteolysis was expressed as Acquired Colorimetric Unit (ACU). One ACU equals to a gain of 1 absorbance unit at $340 \mathrm{~nm}$. Trypsin was used as positive control, while negative controls comprised the absence of the enzyme or venoms.

Hyaluronidase activity was assayed by turbidimetric method using hyaluronic acid (HA) as substrate, according to Di Ferrante [60]. The assay mixture contained $28 \mu \mathrm{L}$ of HA $(0.1 \mu \mathrm{g} / \mu \mathrm{L})$ from human umbilical cord (Sigma-Aldrich), 0.2 M sodium acetate buffer, $\mathrm{pH} 5.6(28 \mu \mathrm{L})$ and $5 \mu \mathrm{g}$ of venoms samples in a final volume of $340 \mu \mathrm{L}$. Mixtures were incubated at $37{ }^{\circ} \mathrm{C}$ for $15 \mathrm{~min}$ and the reaction was stopped by adding $28 \mu \mathrm{L}$ of hexadecyltrimethylammonium bromide (CTAB) in $2 \%$ $\mathrm{NaOH}$. The resulting turbidity was read at $400 \mathrm{~nm}$ and the activity expressed as percentage of hydrolyzed hyaluronic acid, considering that the negative control showed $0 \%$ hydrolysis, or $100 \%$ hyaluronic acid present in the sample. Differences in enzymatic activities between venoms were analyzed using the GraphPad Prism V8.0 software by ANOVA two way $(\mathrm{p}<0.01)$.

\section{Electrophoresis}

In order to compare the protein profiles of the venoms, samples $(100 \mu \mathrm{g})$ of $\mathrm{Pn}-\mathrm{V}, \mathrm{Pp}-\mathrm{V}$, and $\mathrm{Pe}-\mathrm{V}$ were submitted to electrophoresis (Tricine-SDS-PAGE), according to Schägger and Jagow [61], under non-reducing and reducing conditions.

Electrophoresis was performed in a discontinuous vertical system with $15 \%, 10 \%$, and $4 \%$ gels for separating, spacing, and stacking, respectively. Electrophoresis took place overnight at $4{ }^{\circ} \mathrm{C}$, running at $30 \mathrm{~mA}$ in a $0.1 \mathrm{M}$ tricine running buffer, $\mathrm{pH}$ 8.5. Gels were stained overnight with $0.05 \%$ Coomassie Blue G 250, and images were recorded with an Image Scanner III (GE Healthcare).

\section{Fractionation of Phoneutria venoms and purification of toxins}

Fractionation of Phoneutria venoms (Pn-V, Pp-V, and Pe-V) and purification of toxins were carried out according to Richardson et al. [21]. Briefly, lyophilized venom samples (30 mg) were dissolved in $2 \mathrm{~mL}$ of aqueous $0.1 \%$ TFA (solution A) and centrifuged at $5700 \mathrm{x} \mathrm{g}$ for $10 \mathrm{~min}$ at $4{ }^{\circ} \mathrm{C}$. The supernatant was applied onto a preparative Vydac C4 column $(2.2 \times 25 \mathrm{~cm})$ equilibrated with solution $\mathrm{A}$ and eluted with a segmented gradient of solution 
B (100\% acetonitrile containing $0.1 \%$ TFA), at a flow rate of $5 \mathrm{~mL} / \mathrm{min}$ (HPLC). Peptides or proteins were detected at 214 $\mathrm{nm}$. Fractions were manually collected, lyophilized, and stored at $-20^{\circ} \mathrm{C}$ until use.

For the purification process (toxin isolation), two fractions were selected based on similar elution/retention times to those from previous purifications of $P$. nigriventer venom shown to contain the toxins Tx1 and Tx2-6 [21]. These fractions were processed according to Richardson et al. [21]. Initially, the fractions were reconstituted in $10 \mathrm{mM}$ sodium phosphate buffer, pH 4.7 (solution A) and submitted to cation-exchange-HPLC on a GE Hitrap SP column $(0.7 \mathrm{~cm} \times 2.5 \mathrm{~cm})$. The column was equilibrated with solution $\mathrm{A}$ and eluted using a linear gradient of 0 to $100 \%$ of $10 \mathrm{mM}$ sodium phosphate buffer containing 0.5 $\mathrm{M} \mathrm{NaCl}, \mathrm{pH} 4.7$ (solution $\mathrm{B}$ ) at a flow rate of $1 \mathrm{~mL} / \mathrm{min}$.

The main protein components from ion-exchange chromatography were further desalted in an analytical RPHPLC column (218TP54 small pore, $250 \mathrm{~mm}$ x $4.6 \mathrm{~mm}$, Vydac, Grace, Columbia, MD) equilibrated with aqueous $0.1 \%$ TFA. Fractions were eluted with a gradient of 0 to $70 \%$ of solution B $(0.1 \% \mathrm{TFA} / \mathrm{ACN})$ at a flow rate of $1.0 \mathrm{~mL} / \mathrm{min}$.

\section{Mass spectrometry analysis MALDI-TOF analysis}

Molecular masses of components of preparative RP-HPLC fractions were determined by MALDI-TOF MS using a Bruker Autoflex III Smartbeam instrument (Bruker Daltonics, Billerica, MA, USA). External calibration procedures were performed using commercially available standard protein mixtures (Bruker Daltonics, Billerica, MA, USA), according to different mass range: Protein Standard II ( $10 \mathrm{kDa}-70 \mathrm{kDa})$; Protein Calibration Standard I ( $4 \mathrm{kDa}-20 \mathrm{kDa}$ ) and Peptide Calibration Standard II (700 Da-3.5 kDa). Prior to analysis, crude venoms were submitted to ZipTip C4 pipette tips (Millipore Co., Burlington, MA, USA) and eluted with $50 \%(\mathrm{v} / \mathrm{v})$ aqueous ACN containing $0.1 \%(\mathrm{v} / \mathrm{v})$ TFA. Salt-free samples were lyophilized and solubilized in $0.1 \%$ (v/v) aqueous TFA. Next, samples $(0.5 \mu \mathrm{L})$ were spotted on anchorchip target plates and mixed with $0.5 \mu \mathrm{L}$ matrix solution. Three different matrices were used, $\alpha$-cyano-4-hydroxycinnamic acid (HCCA), sinapinic acid (SA) and 2,5-dihydroxybenzoic acid (DHB) matrices that were prepared according to the manufacturer. Briefly, matrices $(10 \mathrm{mg} / \mathrm{mL})$ were prepared solved in aqueous ACN solution (1:2) containing $0.1 \%$ TFA. The percentage of ACN was used according to each matrix (HCCA- 70\%), (SA$40 \%)$ and DHB (20\%). Analyses were performed in different mass ranges (2000 - 125000). MS spectra were acquired under positive linear and/or reflector ion modes using FlexControl software (Bruker Daltonics). The laser power (355 nm) was tuned manually for an optimal signal. Data were processed and analyzed using FlexAnalysis (Bruker Daltonics) and graphics built with SigmaPlot (Systat Software, Inc) and Microsoft Excel. Besides, MALDI/TOF also was used to confirm the purified toxins (Tx1 and Tx2-6) in positive/linear mode (mass range 2-20000 $(\mathrm{m} / \mathrm{z})$ using sinapinic acid as matrix.
In addition, strict criteria were adopted to consider the mass values, of which: (i) the series of the monoisotopic chain or the isolated peak should be conspicuous; (ii) the difference between peaks of the same monoisotopic series should be $1 \mathrm{Da}$; (iii) intensity of the components was $>5.0 \times 10^{3}$ and (iv) less intense peaks were excluded, for their mass differences could indicate common events in the experiment, such as methylations, oxidations, among others.

\section{Amino acid sequence}

Purified toxins were subjected of their N-terminus by employing the automated Edman degradation sequencing technique, using a Shimadzu PPSQ-21A (Tokyo, Japan). Subsequently, toxins were subjected to an in-solution digestion protocol was used as described by Sanson et al. [62]. Briefly, samples containing 50 $\mu \mathrm{g}$ protein were solubilized in $25 \mathrm{mM}$ ammonium bicarbonate (AMBIC) followed by addition of RapiGest SF Surfactant (Waters, UK) to a final concentration of $0.06 \%(\mathrm{w} / \mathrm{v})$, and heated at $80{ }^{\circ} \mathrm{C}$ for $10 \mathrm{~min}$. Subsequently, the samples were reduced using 3.3 $\mathrm{mM}$ dithiotreitol (DTT) for $10 \mathrm{~min}$ at $60^{\circ} \mathrm{C}$ and alkylated with $9.4 \mathrm{mM}$ iodoacetamide (IAA) at room temperature for $45 \mathrm{~min}$, in the dark. MS-grade trypsin (Promega) was added at an enzyme/ substrate ratio of 1:50 and digestion proceeded at $37^{\circ} \mathrm{C}$ overnight. Trypsin inactivation and surfactant precipitation were achieved by addition of $0.5 \%$ TFA followed by incubation for $40 \mathrm{~min}$ at $37^{\circ} \mathrm{C}$. Finally, the samples were centrifuged for $15 \mathrm{~min}$ at 20000 $\mathrm{x} g$ at $7{ }^{\circ} \mathrm{C}$, and the supernatants were stored at $-20^{\circ} \mathrm{C}$ until use.

Samples $(2 \mu \mathrm{L})$ of the supernatants of each trypsinized toxin were subjected to liquid chromatography coupled to mass spectrometry (LC-MS /MS) analyses in a nanoUHPLC UltiMate 3,000 (Dionex, San Jose, USA) interfaced with a Q Exactive mass spectrometer (Thermo Scientific ${ }^{\circledast}$, Bremen, Germany), using a Nanospray Flex Ion source and a nano-bore stainless steel emitter $(150 \mu \mathrm{m}$ OD $30 \mu \mathrm{m}$ ID, Proxeon, Thermo Scientific, Bremen, Germany). A peptide clean-up step was first achieved using a Nano-Trap Acclaim PepMap100 C18 column $(100 \mu \mathrm{m}$ $\times 2 \mathrm{~cm}, 5 \mu \mathrm{m}, 100 \AA$, Thermo Scientific, Whaltham, MA, USA), followed by sequential elution peptides bound to EASY-Column ${ }^{\mathrm{m}}$ Capillary C18 Columns $(75 \mu \mathrm{m} \times 10 \mathrm{~cm}, 3 \mu \mathrm{m}, 120 \AA$ A, Thermo Scientific) using an acetonitrile gradient. Formic acid at $0.1 \%$ (solution $\mathrm{A}$ ) and $80 \%$ acetonitrile plus $0.1 \%$ formic acid (solution B) were used as eluents. The column was equilibrated for $3 \mathrm{~min}$ with solution A at a flow rate of $0.3 \mu \mathrm{L} / \mathrm{min}$. Elution proceeded with $3.8 \%$ solution B and gradually increased to $99 \%$ in $152 \mathrm{~min}$, remaining so for another $10 \mathrm{~min}$. Mass spectrometric analysis was performed on positive mode under $3.45 \mathrm{kV}$ with interface temperature kept at $250^{\circ} \mathrm{C}$. Spectra were acquired with a MS1 resolution of 70,000, maximum injection time of $120 \mathrm{~ms}$, AGC target $1 \times 10^{6}$, scan range $300-2000 \mathrm{~m} / z$, and charge states $\geq+2$ and $\leq+5$. Peptide fragmentation of up to 12 most intense ions was carried out by high energy collisional dissociation. MS/ MS spectra were obtained under 35,000 resolution, isolation window $2 \mathrm{~m} / z$, normalized collision energy of $30 \mathrm{~V}$, and dynamic exclusion time of $40 \mathrm{~s}$. 
The peptides were identified using the PEAKS Studio 8.5 program (Bioinformatics Solutions Inc, Canada) through mass spectral data interrogation searching against a compilation of toxin sequences from animals' venoms deposited in NCBI database (185,632 sequence) (NCBI- https://www.ncbi.nlm. nih.gov/) and all sequences in ArachnoServer (1,500 sequence) (http://www.arachnoserver.org/) (187,132 sequences total, downloaded on 16 November 2020). The following search parameters were considered: up to 2 missed trypsin cleavage sites were accepted; a precursor error of $10 \mathrm{ppm}$; and product error of $0.1 \mathrm{Da}$. Carbamidomethylation of cysteine residues $(+57.02 \mathrm{Da})$ and methionine oxidation $(+15.99 \mathrm{Da})$ were set as fixed and variable modifications, respectively. Multiple sequence alignment was performed by the Clustal Omega/EMBL-EBI (https://www.ebi.ac.uk/Tools/msa/clustalo/).

\section{Whole-cell patch clamp}

Toxin-1 isoforms (PnTx1, PpTx1 and Pe-Tx1) isolated from the venoms of different Phoneutria species were submitted to electrophysiological assays in order to verify their action on sodium channels. The experiments were carried out at room temperature $\left(20-22{ }^{\circ} \mathrm{C}\right)$ in whole-cell patch-clamp mode with a HEKA amplifier (EPC10 USB, Germany), using HEK293 cells held at $-80 \mathrm{mV}$. The $\mathrm{P} / 4$ protocol was used to subtract capacitance and linear leak currents. Patch pipettes resistance varied between $1.2-2.5 \mathrm{M} \Omega$. During the test pulse, the membrane was depolarized to $0 \mathrm{mV}$ for $50 \mathrm{~ms}$, following a pre-pulse to -100 $\mathrm{mV}$ for $100 \mathrm{~ms}$, every 5 seconds.

HEK293 cells permanently expressing $\mathrm{Na}_{\mathrm{v}} 1.6$ channels were incubated at $37{ }^{\circ} \mathrm{C}$ in $5 \% \mathrm{CO}_{2}$, in high glucose DMEM supplemented with $10 \%$ fetal bovine serum and $1 \%$ glutamax. Cells were split once a week using trypsin-EDTA solution $(0.05 \%$, Gibco), and the experiments carried out $24-48 \mathrm{~h}$ afterwards. The external solution used to acquire the data was: $130 \mathrm{mM} \mathrm{NaCl}$, $5.4 \mathrm{mM} \mathrm{KOH}, 1.8 \mathrm{mM} \mathrm{CaCl}, 1 \mathrm{mM} \mathrm{MgCl}_{2}, 10 \mathrm{mM}$ glucose, $10 \mathrm{mM}$ HEPES, $\mathrm{pH}$ 7.4. Pipette solution composition was: 100 mM CsF, $10 \mathrm{mM} \mathrm{NaCl}, 5 \mathrm{mM} \mathrm{MgCl}$, $11 \mathrm{mM}$ EGTA, $10 \mathrm{mM}$ TEA-Cl, 10 mM HEPES, pH 7.2.

Toxin-1 from the venoms of Pn-V (PnTx1, $1 \mu \mathrm{M}), \mathrm{Pp}-\mathrm{V}$ (PpTx1, $3.25 \mu \mathrm{M})$, and $\mathrm{Pe}-\mathrm{V}(\mathrm{PeTx} 1,1 \mu \mathrm{M})$ were diluted in external solution and delivered (flow $160-200 \mu \mathrm{L} / \mathrm{min}$ ) by means of a perfusion system (VM4, ALA Scientific Instruments) with the outlet placed near the cell. Bovine serum albumin $(0.1 \%$; Sigma-Aldrich, ref. 7030) was added to the toxin solutions to avoid adsorption. Current recovery was measured $350 \mathrm{~s}$ after the beginning of washout.

\section{Results}

\section{Enzymatic activity of Phoneutria venoms}

Analysis of the gelatinolytic and hyaluronidase activities of $\mathrm{Pn}-\mathrm{V}, \mathrm{Pp}-\mathrm{V}$, and $\mathrm{Pe}-\mathrm{V}$ were carried out through zymography using gelatin and hyaluronic acid as substrates. All three venoms exhibited prominent gelatinolytic and hyaluronidase activities, evidenced by the large colorless bands in the gels (Figure $1 \mathrm{~A}$ and 1B). These bands presented similar migration in both zymograms. A similar degradation pattern was observed for the gelatinolytic activity of all venoms. In contrast, the hyaluronidase activity of $\mathrm{Pp}-\mathrm{V}$ was higher compared to the other two venoms. To quantify and compare proteolytic and hyaluronidase activities from the crude venoms, we performed a colorimetric test on dimethyl casein and turbidimetric assays, respectively (Figure $1 \mathrm{C}$ and 1D). The results corroborated the zymography data and showed similar specific activity for all the venoms concerning dimethyl casein activity (Figure 1C), and some differences for that of hyaluronidase. $\mathrm{Pp}-\mathrm{V}$ and $\mathrm{Pe}-\mathrm{V}$ degraded HA 6.5 and 3.8 times more efficiently than Pn-V, respectively (Figure 1D).

\section{Protein profile of Phoneutria venoms}

The protein profiles of the crude venoms from the three species were compared through SDS-PAGE. The analysis revealed that the venoms appear to be similar regarding the number of components ( $\sim 40$ protein bands are visualized) and the pattern of mass distribution (2-175 kDa), with the majority migrating in the mass range below $6.0 \mathrm{kDa}$. However, there are visible differences in the intensity of some components in these venoms (Figure 2A).

In addition, we compared preparative reversed-phase HPLC profiles of the venoms, using an extended gradient of acetonitrile in $0.1 \%$ aqueous TFA. The profiles obtained were quite similar, with venoms fractionating into 70 main protein components eluted mostly between $\sim 20$ - 55\% acetonitrile (Figure 2B). These profiles revealed peaks with elution times and features matching the toxins PnTx1 and PnTx2-6 previously isolated from the $P$. nigriventer venom [21], which were eluted with roughly 30 and $50 \%$ acetonitrile, respectively (Figure $2 \mathrm{~B}$ ).

Furthermore, the similarity between these Phoneutria venoms was corroborated by the comparison between the masses of the fractions obtained by preparative RP-HPLC, identified by MALDI-TOF (Figure 2C). In accordance with SDS-PAGE profiles, these results show that low molecular weight proteins $(\leq 10 \mathrm{kDa})$ represent the largest proportion of the components of the venoms, although some molecules are distributed throughout the high molecular mass range.

\section{Toxin isolation and chemical characterization}

In order to ascertain the presence of Tx1 (PnTx1, PpTx1 and PeTx1) and Tx2-6 (PnTx2-6, PpTx2-6 and PeTx2-6) isoforms, fractions from preparative RP chromatography with elution times corresponding to these toxins (Figure 2B) were subsequently fractionated on cation-exchange-HPLC. The major protein peak obtained in this chromatography was eluted as a symmetrical peak in RP-HPLC (data not shown). Mass spectrometry analysis of these samples on a MALDI/TOF instrument revealed a high degree of homogeneity. In $\mathrm{Pn}-\mathrm{V}, \mathrm{Pp}-\mathrm{V}$, and $\mathrm{Pe}-\mathrm{V}$ signals were evidenced at $\mathrm{m} / z$ values of 8594,8598 and $8628 \mathrm{Da}$, there were also signals of 5288, 5288, and $5160 \mathrm{Da}$, for Pn-V, Pp-V, and Pe-V, respectively, all values described for Tx2-6 toxins (Figure 3). 
A

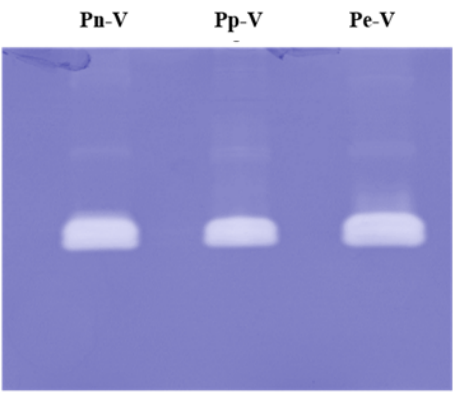

$\mathrm{C}$

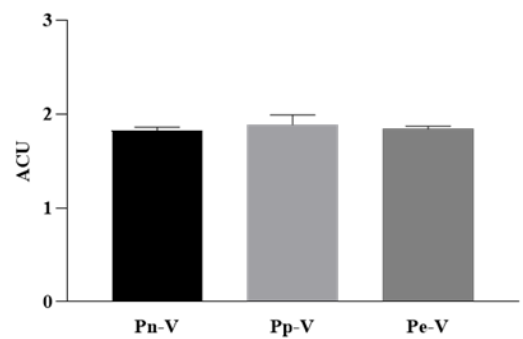

B

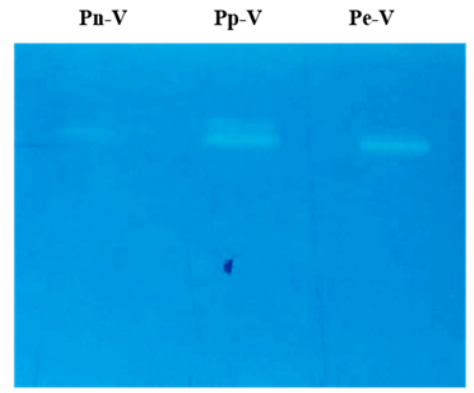

$\mathrm{D}$

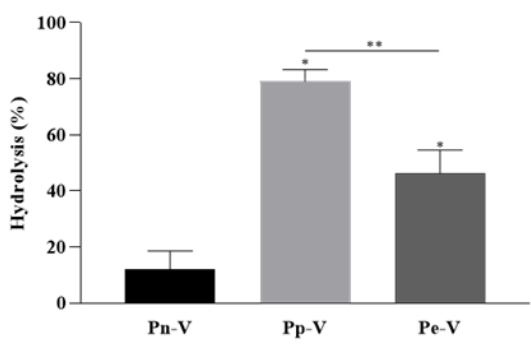

Figure 1. Enzymatic activities of P. nigriventer (Pn-V), P. pertyi (Pp-V) and P. eickstedtae (Pe-V) venoms. Zymography of crude venoms (50 $\mu \mathrm{g})$ in (A) $12.5 \% \mathrm{SDS}$ PAGE 0.1\% gelatin and (B) 12.5\% SDS-PAGE 1.5\% HA. Enzymatic activities measured by spectrophotometry with (C) dimethyl-casein and (D) hyaluronic acid as substrates. Data are presented as mean $\pm \mathrm{SEM} ; \mathrm{p}<0.01$ represented with (*) for $\mathrm{Pp}-\mathrm{V} / \mathrm{Pe}-\mathrm{V}$ versus $\mathrm{Pn}-\mathrm{V}$ and with (**) for $\mathrm{Pp}-\mathrm{V}$ versus $\mathrm{Pe}-\mathrm{V}$.

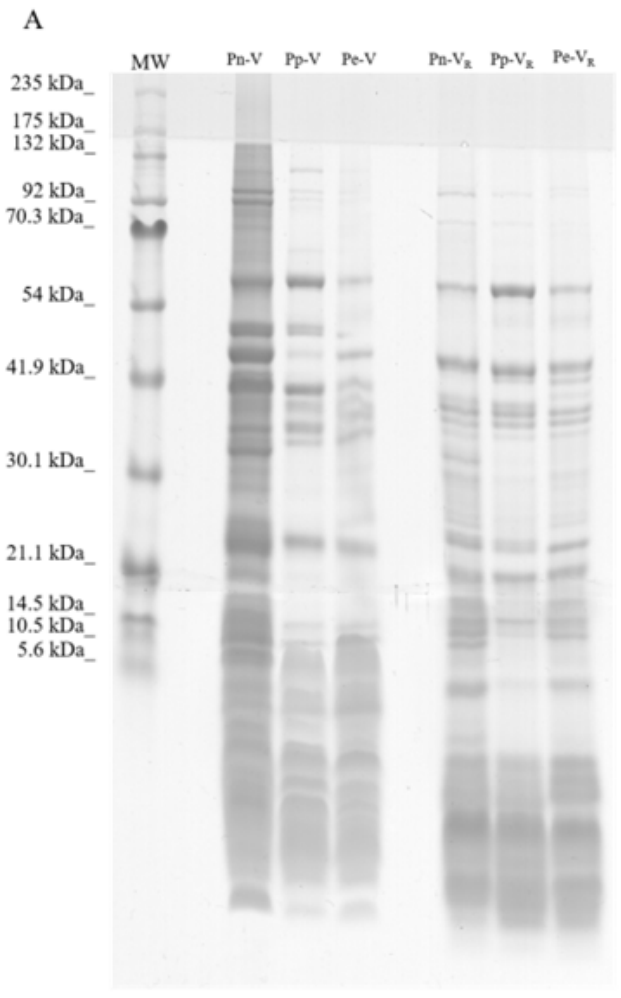

B
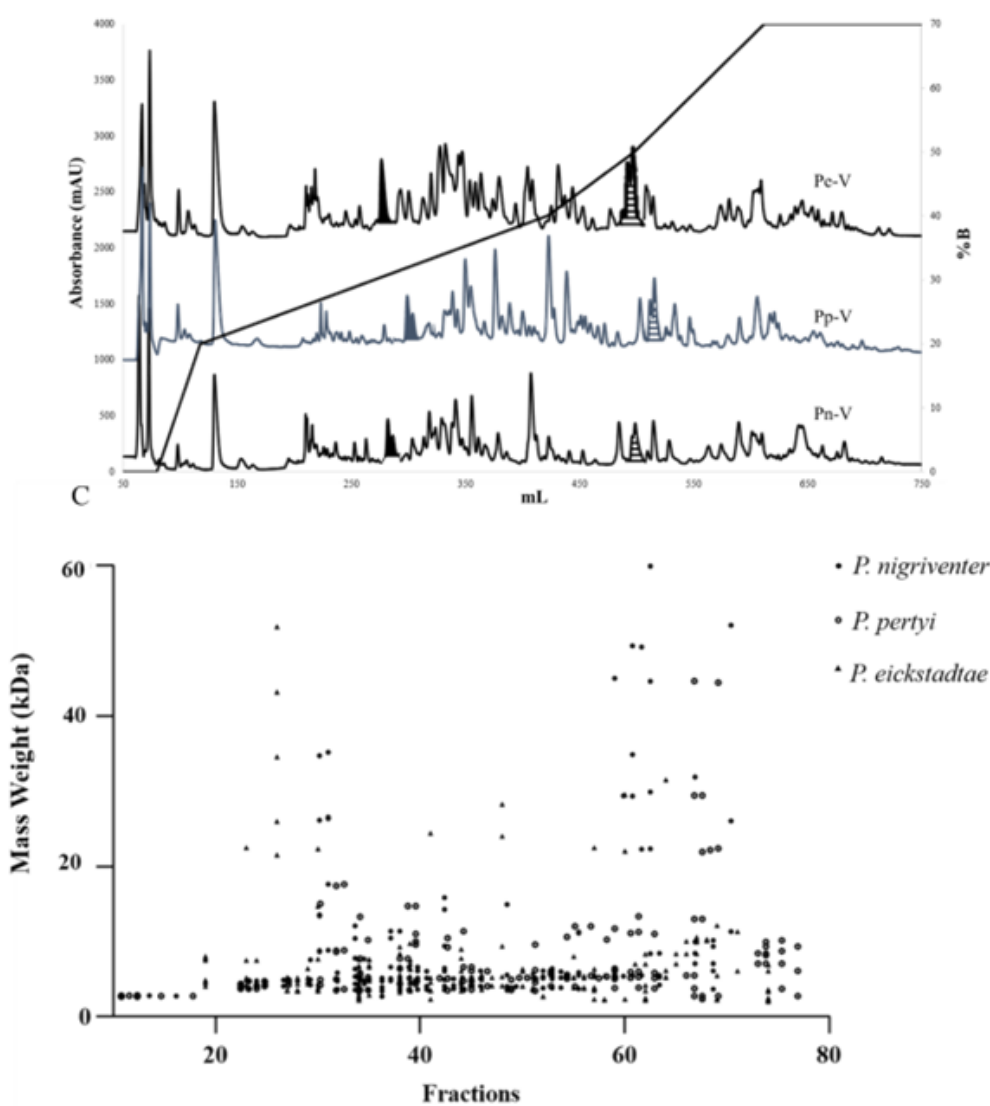

Figure 2. Comparison of the protein profiles of the crude venoms of P. nigriventer (Pn-V), P. pertyi (Pp-V) and P. eickstedtae (Pe-V). (A) SDS-PAGE (discontinuous vertical system with $15 \%, 10 \%$, and $4 \%$ for separating, spacing, and stacking gels, respectively - $100 \mu \mathrm{g}$ of each venom), under non-reducing (left) and reducing ( $\beta$-mercaptoetanol $4 \%, v / v$ ) (right) conditions. The positions of molecular mass markers are indicated on the left. The gel was stained with Coomassie brilliant blue. (B) RP-HPLC profile of crude venoms $(30 \mathrm{mg})$ on preparative Vydac C4 column $(2.2 \mathrm{~cm} \times 25 \mathrm{~cm})$. The column was equilibrated using solution A [0.1\% TFA (v/v) in ultrapure water] and eluted using solution B [0.1\% TFA (v/v) in acetonitrile]. Protein elution was monitored by absorbance at $214 \mathrm{~nm}$. Hachured and striped peaks indicate the fractions corresponding to Tx1 and Tx2-6, respectively. (C) Mass distribution of the fractions from preparative RP-HPLC. 


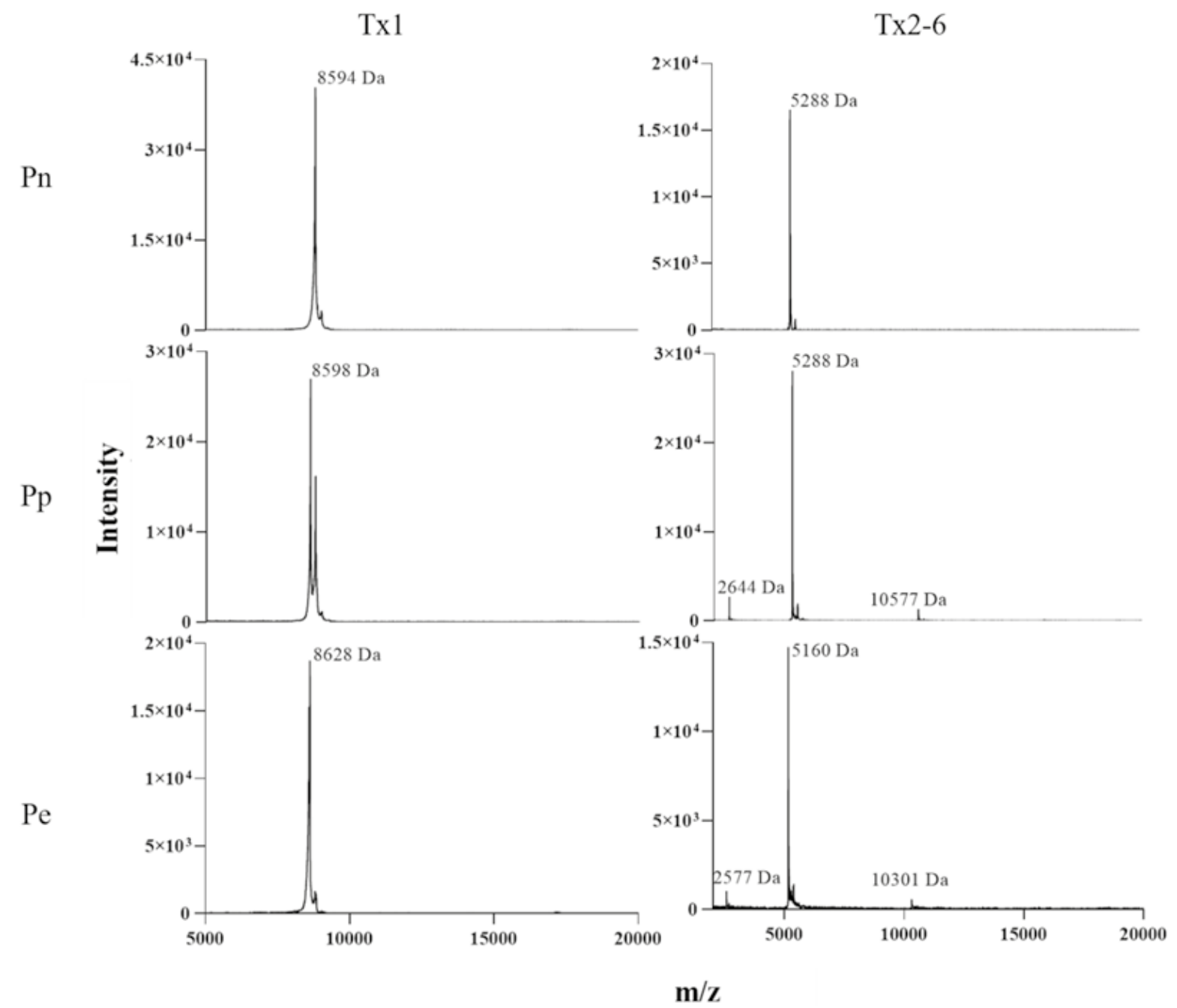

Figure 3. Chemical analyses of purified toxins. MS spectra obtained, respectively, for toxins exhibiting dimer formation and double charge on MALDI/TOF in positive/linear mode - mass range 2-20000 ( $\mathrm{m} / \mathrm{z})$ using sinapinic acid as matrix.

In order to confirm the toxin sequences, the $\mathrm{N}$-terminal were determined by Edman degradation. The Tx1 isoforms (PnTx1, $\mathrm{PpTx} 1$ and PeTx1) were obtained 20 amino acids residues, while to Tx2-6 isoforms (PnTx2-6, PpTx2-6 and PeTx2-6), 15 amino acids residues (Figure 4). Besides, amino acid sequences of tryptic fragments were obtained by database interrogation of mass spectral data (Figure 4). Using the venom sequences database from NCBI and spider toxins from ArachnoServer, we found that the peptide fragments showed identity to PnTx1 (P17727-1) and PnTx2-6 (P29425). In addition, the purified fractions of Pn-V and $\mathrm{Pp}-\mathrm{V}$ also present peptides were identified from PnTx2-5 (P29424) and Pn21-A (O76198) isoforms (Figure 4).

Sequence coverage percentage obtained for PnTx1, PpTx1 and PeTx 1 were $89.9 \%, 45.6 \%$ and $45.6 \%$, respectively, while for all Tx2-6 and two Tx2-5 isoforms obtained were $100 \%$. On the other hand, the coverage of Pn21-A and Pp21-A were 92.6\% and $20.4 \%$, respectively. Already identity was $100 \%$ for all peptides obtained in that work (Figure 4). Therefore, $\mathrm{Pp}-\mathrm{V}$ and $\mathrm{Pe}-\mathrm{V}$ contain isoforms of the Tx1 and Tx2-6, moreover, in Pp-V was possible to still find PpTx2-5 Pn21-A isoform.

\section{Effect of Phoneutria toxins on Nav1.6 sodium channels}

To verify whether different isoforms of the Tx1 toxin would exhibit the same effect, we compared their ability at blocking $\mathrm{Na}_{\mathrm{v}} 1.6$ sodium channels (Figure 5). Toxins were tested at concentrations of $1 \mu \mathrm{M}$ for PnTx 1 and PeTx 1 and $3.25 \mu \mathrm{M}$ for PpTx1. Although PpTx1 concentration was slightly higher, the effect was already supramaximal and had no influence in the maximum blockage. All toxins PnTx1, PpTx1 and PeTx1 were able to block the channels however the kinetics of blockage and recovery washout were different among the isoforms. PnTx1 had the slowest effect, suggesting that some amino acids that compose its binding site might be protected inside the channel structure, but once they are exposed, the toxin bind to the channel and it was hard to wash it out (Figure 5A). On the other hand, PpTx1 and PeTx1 did not appear to bind to the channels (on-rate) in a voltage-dependent way, with maximum inhibition being reached after few pulses (Figure 5A). At $350 \mathrm{~s}, 27.4 \pm 3.91 \%$ and $37.25 \pm 4.77 \%$ of the current was recovered after PpTx 1 and PeTx1 washout, respectively (Figure 5B). Once these toxin isoforms were bound to the channels, the off-rate was slow and 
Tx1 >sp|P17727|TXL1_PHONI Mu-Ctenitoxin-Pn1a OS=Phoneutria nigriventer

\begin{tabular}{|c|c|c|c|c|c|c|c|c|c|c|}
\hline & Cov (8) & ID $(8)$ & 10 & 20 & 30 & 40 & 50 & 60 & 70 & MW (Da) \\
\hline Reference: & 100.0 & 100.0 & AELTSCFPVG & HECDGDASNC & NCCGDDVYCG & CGWGRWNCKC & KVADQSYAYG & ICRDKVNCPN & RHLWPAKVCK KPCRRNCGG & 8594 \\
\hline Pn: & 89.9 & 100.0 & AELTSCFPVG & HECDGDASNC & NCCGDDVYCG & CGWGRWNCRC & RVADQSYAYG & ICKDKVNCPN & RHLWPAKVCK $\mathrm{K}$ & 8594 \\
\hline Pp: & 45.6 & 100.0 & AELTSCFPVG & HECDGDASNC & & & RVADQSYAYG & ICKDKV & & 8598 \\
\hline $\mathrm{Pe}:$ & 45.6 & 100.0 & AELTSCFPVG & HECDGDASNC & NCCGDDVYCG & CGWGRW & & & & 8628 \\
\hline
\end{tabular}

Tx2-6 >sp|P29425|TX36A_PHONI Delta-Ctenitoxin-Pn2a OS=Phoneutria nigriventer

\begin{tabular}{|c|c|c|c|c|c|c|c|c|}
\hline & Cov (8) & ID (8) & 10 & 20 & 30 & 40 & 48 & MW (Da) \\
\hline Reference: & 100.0 & 100.0 & ATCAGQDQPC & KETCDCCGER & GECVCGGPCI & CRQGYFWIAW & YRLANCKK & $5288^{\circ}$ \\
\hline Pn: & 100.0 & 100.0 & ATCAGQDQPC & KETCDCCGER & GECVCGGPCI & CRQGYFWIAW & YRLANCKK & 5288 \\
\hline Pp: & 100.0 & 100.0 & ATCAGQDQPC & KETCDCCGER & GECVCGGPCI & CRQGYFWIAW & YRLANCKK & 5288 \\
\hline Pe: & 100.0 & 100.0 & $\overline{A T C A G Q D Q P C}$ & KETCDCCGER & GECVCGGPCI & CRQGYFWIAW & YKLANCKK & 5160 \\
\hline
\end{tabular}

Tx2-5 >tr|P29424| _ PHONI Delta-Ctenitoxin-Pn2C OS=Phoneutria nigriventer

\begin{tabular}{|c|c|c|c|c|c|c|c|c|}
\hline & $\operatorname{Cov}(8)$ & ID ( 8$)$ & 10 & 20 & 30 & 40 & 48 & MW (Da) \\
\hline Reference: & 100.0 & 100.0 & ATCAGQDQTC & KVTCDCCGER & GECVCGGPCI & CRQGNFLIAW & YRLASCRK & $5116^{2}$ \\
\hline Pn: & 100.0 & 100.0 & ATCAGQDQTC & KVTCDCCGER & GECVCGGPCI & CRQGNFLIAW & YKLASCKK & \\
\hline Pp: & 100.0 & 100.0 & ATCAGQDQTC & KVTCDCCGER & GECVCGGPCI & CRQGNFLIAN & YKLASCKK & \\
\hline
\end{tabular}

Pn21-A >sp|076198|TX34B_PHONI U2-Ctenitoxin-Pn1b oS=Phoneutria nigriventer

\begin{tabular}{|c|c|c|c|c|c|c|c|c|c|}
\hline & Cov (8) & ID ( 8$)$ & 10 & 20 & 30 & 40 & 50 & 54 & MW (Da) \\
\hline Reference: & 100.0 & 100.0 & ATCAGQDKPC & KETCDCCGER & GECVCALSYE & GKYRCICRQG & YVWIAWYKLA & SCRK & $6080^{*}$ \\
\hline Pn: & 92.6 & 100.0 & ATCAGQDKPC & KETCDCCGER & GECVCALSYE & GKY & YVWIAWYKIA & SCKR & \\
\hline PP: & 20.4 & 100.0 & & KETCDCCGER & $\mathrm{G}$ & & & & \\
\hline
\end{tabular}

Figure 4. Alignment of the partial amino acid sequence of toxins identified. Cysteines (Cys, C) residues are highlighted in gray color. Reference: Sequence, accession code and name of P. nigriventer's toxin deposited in Uniprot database. The size of identified peptides are highlighted in yellow, green, blue and pink. MW: molecular weight (Da). *Theoretical mass value obtained from PeptideMass (www.expasy.com). Mass value according to Richardson et al. [21]. Underlined sequences were obtained by Edman Degradation method. Positions of cysteine residues (labeled in red) were inferred by homology.

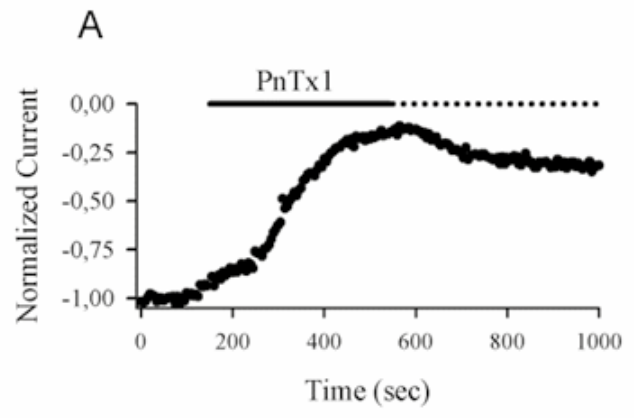

B

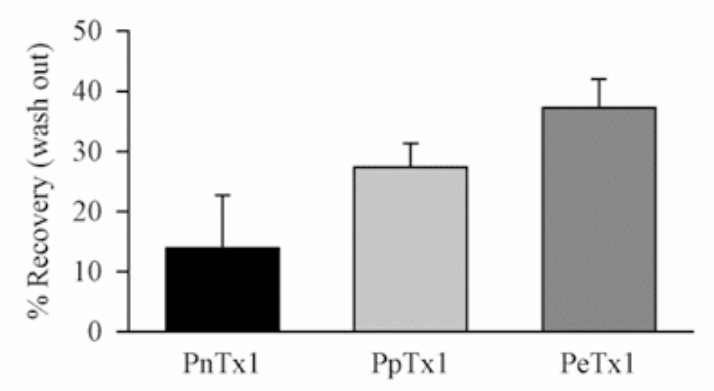

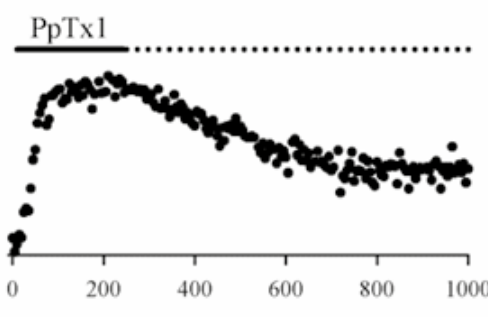

Time (sec)

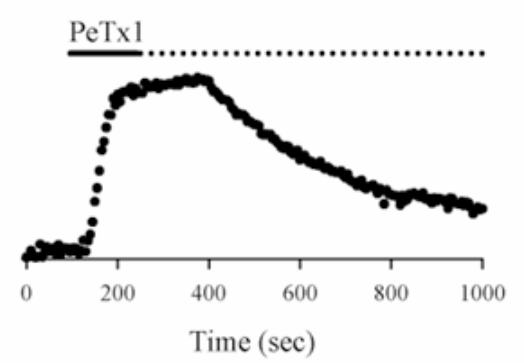

C

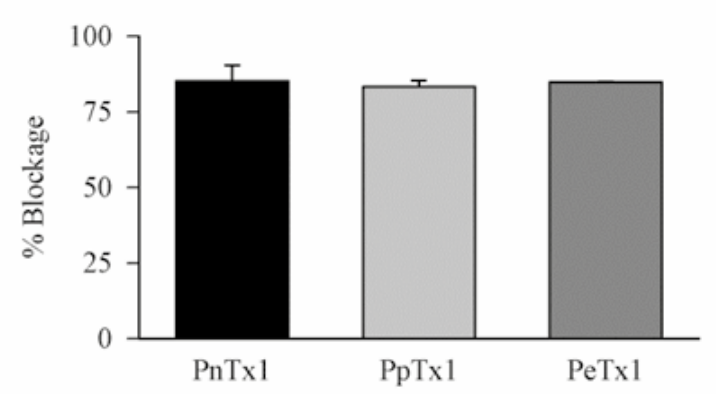

Figure 5. Different Tx1 isoforms block Nav1.6 sodium current reversibly. (A) Time course of the blockage of the sodium current peak by Tx1 isoforms from different Phoneutria species and washout kinetics. (B) Recovery of sodium current blockage after 350 s of washout. (C) Percentage of Nav1.6 sodium currents blockage by $\mathrm{T} x 1$ isoforms after stabilization. 
the recovery after washout incomplete, at least for the duration of the experiment (Figure 5B). The blockage was $85 \%$ for all of them (Figure 5C), even for PpTx1 at a higher concentration, suggesting that saturation had been reached.

\section{Discussion}

Animal venoms contain toxic components that induce different physio-pharmacological effects by acting on molecular targets, showing immense biotechnological potential. Some toxins that act on different types of ion channels, with the considerable advantage of binding selectively, have been identified in the venom of the spider P. nigriventer[17]. Possibilities for the development of new drugs based on these toxins, as well as their use for a deeper understanding of complex physiological processes, have been described[35,36,50,51,63].

In spite of the potential pharmaceutical benefits offered by $P$. nigriventer toxins, there is limited information on venoms of the same genus, and their toxins remain poorly characterized. In order to obtain more information on toxins of other species from the Phoneutria genus and assess their biotechnological potential, we proposed the present study. Through enzymatic activities, SDS-PAGE, HPLC profiles, and mass spectrometry analysis, we conducted a comparative investigation on the protein profiles of crude venoms of three different spiders of the genus Phoneutria: P nigriventer, P. eickstadae, and P. pertyi, correlating them with biological activities. In addition, two molecules of Pn-V toxins were purified, one of which had its action on sodium channels analyzed.

As proteolytic and hyaluronidase activities are common in animal venoms, we analyzed the gelatinolytic and hyaluronidase activities of Phoneutria venoms. We observed that these venoms exhibited gelatinolytic activity with a similar degradation pattern, whereas hyaluronidase activity appears to be more potent in $\mathrm{Pp}-\mathrm{V}$ and $\mathrm{Pe}-\mathrm{V}$ compared to $\mathrm{Pn}-\mathrm{V}$.

Venom proteases are multifunctional compounds, being related from allergic reactions and blood coagulation to toxin processing. Proteases have already been identified in several spider venoms, e.g., a protease from the venom of Loxosceles sp. genus is associated with injury to blood vessels, impaired endothelial cell adhesion, and cell death induced by this venom $[64,65]$. Serine proteases were described in P. nigriventer, $P$. reidyi, and $P$. keyserlingi venoms, being associated with post-translational modification of venom components [21]. Serine proteases (e.g., allergen), metalloproteinases (e.g., astacin, zinc metalloproteinase, and neprilysin), and cysteine-rich secretory protein (CRISP) were found in the Grammostola iheringi spider venom [8].

The presence of hyaluronidases has also been identified in the venoms of various animals such as reptiles and arthropods, as well as from other sources, such as fungi and bacteria, mammalian organs, and corporal fluids [66]. These enzymes hydrolyze the glycosaminoglycan that form the extracellular matrix, having hyaluronic acid (HA) as their preferred substrate. In animal venoms, these glycosidases are thought to increase plasma membrane absorption and reduce viscosity, ensuring that the toxic molecules can reach their targets in the victim's organism, consequently contributing to the overall toxicity of these venoms.

Therefore, hyaluronidases act as spreading factors for the toxins during envenomation. The enzymatic action of hyaluronidases is also associated with several pathophysiological processes, as fertilization, embryogenesis, angiogenesis, wound healing, sepsis, metastasis, among others [67]. Due to these effects, hyaluronidases show great biotechnological potential, having been used for clinical applications, e.g., to reduce cancer progression and in ophthalmological procedures [66].

Comparison of the SDS-PAGE and RP-HPLC profiles of venoms of the three Phoneutria species showed similarity in the overall venom composition. When these venoms were subjected to separation by electrophoresis, a high number of similar proteins that migrated as protein bands with apparent molecular weights ranging from $2-175 \mathrm{kDa}$, under reducing and non-reducing conditions, was revealed (Figure 2A). As expected, most components displayed molecular weights lower than $6 \mathrm{kDa}$ (Figure 2A), corresponding to neurotoxins commonly found in arthropod venoms. In addition, SDS-PAGE showed less complexity under non-reducing conditions than is typical under reducing conditions (range 15 - $40 \mathrm{kDa}$ ), indicating the presence of proteins with more than one polypeptide chain and linked by disulfide bonds, or protein complexes.

Richardson and cols. demonstrated that when $P$. nigriventer, $P$. keserling and $P$. reidyi venoms were subjected to $2-\mathrm{D}$ electrophoresis, approximately 80 spots were visible in each case [21]. However, mass fingerprinting by RP-HPLC/mass spectrometry analysis revealed that each venom contains over 150 different molecules [68]. In the present work, 142, 149, and 214 mass values $(>2 \mathrm{kDa})$ were detected for $\mathrm{Pn}-\mathrm{V}, \mathrm{Pp}-\mathrm{V}$, and $\mathrm{Pe}-\mathrm{V}$, respectively, when each fraction of these venoms from preparative RP-HPLC were subjected to MALDI/TOF analysis. Using a similar approach, Escoubas et al. [69] found 633 peptides components in the venom from Atrax robustus spider (male) and 1018 in the Hadronyche versuta (female). While Duran et al. [70] recorded 83 components in Hadronyche valida venom. Li et al. [19] compared the venom from two fishing spiders of Dolomedes genus, for D. mizhoanus were described 302 components, while for D.sulfurous, they found 378 peptides [19,69,70].

Therefore, our data suggest that the venoms studied show general similarity in their components, as well as minor qualitative and quantitative differences between them. The venoms of Phoneutria species exhibited the overall common features: (i) number of highly similar protein peaks (on average 80) were eluted with comparable elution/retention times in preparative RP-HPLC; (ii) electrophoretic profiles and mass scatter plot analysis showed a predominance of low molecular mass molecules $(\sim 6.0 \mathrm{kDa})$; (iii) multiple masses per fraction and (iv) several fractions containing masses with similar values that were co-eluted simultaneously, suggesting the presence of many isoforms. 
Intraspecific differences in animal venom composition are frequently noticed and several factors have been shown to influence it, such as food availability, season, environment, stages of maturation, and sex of each specimen [20,21]. In addition, the post-translation process (proteolysis and C-terminal alterations) is a recurrent source for this intraspecific variability among venoms $[68,71]$. Besides, the variability among venoms of species from the same genus has also been described. This interspecific variability results in isoforms of the same toxin, with strong similarities in their structures and biological activities [21,71]. Furthermore, according to the literature, this venom variation can be highly useful as a marker to identify species [72-74]. Despite of some studies have reported that amino acid substitution alters the functional activity, it is not clear if in our approach we have the effects of these modifications, such as evolutionary implications. Further studies will be necessary to confirm this.

Considering the existence of intraspecific differences and the variability among venoms of species from the genus Phoneutria, in this study the samples of venoms were prepared from animals of both sexes, sent to Ezequiel Dias Foundation Aracnidarium by the population or collected from different habitats. To confirm the presence of the isoforms and the functional similarity of the toxins from venoms of different species, two fractions from preparative RP- HPLC, eluted with $~ 30$ and 50\% acetonitrile (Figure 2B), which correspond to the toxins PnTx1 and PnTx2-6 were fractioned by ion exchange and analytical reversed-phase chromatography.

After these chromatographies the mass spectrometry analysis was carried out (MALDI/TOF and electrospray) of purified toxins revealed the presence of Tx1 and Tx2-6 isoforms for all three species of Phoneutria studied. We found masses of 8594, 8598, and $8628 \mathrm{Da}$ for PhTx1 isoforms, while for PhTx26 isoforms the mass values were 5288, 5288, and $5160 \mathrm{Da}$ for $\mathrm{Pn}-\mathrm{V}, \mathrm{Pp}-\mathrm{V}$, and $\mathrm{Pe}-\mathrm{V}$, respectively, using MALDI/TOF. As far as we know the literature does not provide explanation as to why the theoretical mass observed for both Tx1 and Tx2-6 (monoisotopic mass $=8663$ and 5294) does not match the experimental values obtained (monoisotopic mass $=8594$ and 5288) for any of the sequences in the investigated species. For Tx2-6 from $P$. eickstedtae $(\mathrm{Pe})$ the mass difference is even greater (monoisotopic mass $=5160$ ). This experimental mass value was reconfirmed by the use of three distinct matrices for MALDI technique. As shown in Figure 1, we have detected proteolytic activities in the three venom extracts, therefore this mass difference might be attributed to post-translational processing of the respective toxin.

PnTx1 and PnTx2-6 are the best studied toxins from $P$. nigriventer. PnTx1 was the first neurotoxin identified from the venom of Phoneutria species [75]. This toxin is composed of 78 amino acid residues (MW 8594.6 Da) cross-linked with 7 disulfide bonds, representing about $0.45 \%$ of the whole venom. It is a reversible inhibitor of neuronal sodium channels (Nav1.2/ SCN2A) that binds in proximity to site 1 and displays increasing affinity as the membrane potential is depolarized. PnTx1 induces excitatory symptoms and spastic paralysis in mice $[32,76,77]$.
PnTx2-6 (MW $5288 \mathrm{Da})$ contains 48 amino acids, of which 10 are cysteine residues [29]. This toxin modifies the kinetics of sodium channel inactivation by shifting the voltage dependence of activation towards more hyperpolarized potentials, thus increasing sodium influx [78]. Furthermore, PnTx2-6 was found to induce priapism, representing one the symptoms of envenomation by $P$. nigriventer [21,24]. Due to such effects on penile erection, PnTx2-6 has shown good perspectives for clinical application on erectile dysfunction treatment. PnTx2-6 modulates the nitric oxide (NO)/cyclic GMP pathway, resulting in increased release of NO in the corpus cavernosum tissue, potentially causing penile erection $[24,35,36]$. Based on the active portion of the native toxin, PnTx2-6 was used as a model to design a 19 amino acid residue peptide, termed PnPP-19, which was able to potentiate erection both in vivo and ex vivo, in mice. Besides, this synthetic peptide neither showed toxicity, nor affected sodium channels or rat hearts, and also showed low immunogenicity [24,79]. These findings make PnPP-19 a promising molecule, and this compound is under investigation for the development of drugs for the treatment of erectile dysfunction. Since our results showed the PpTx2-6 and PeTx2-6 share 100\% identity with PnTx2-6, it is suggested these peptides kept priapism effect and also could be used to drug design. However, it would be necessary more assays to ascertain this hypothesis.

Finally, to verify whether the PhTx1 isoforms are functionally similar to PnTx1, we examined their effect on sodium channels expressed in HEK293 cells. Like PnTx1, PeTx1 and PpTx1 isoforms blocked Nav1.6 currents (Figure 5). However, the kinetics of blockage and washout were quite different among the isoforms. These findings are consistent with small alterations in mass values, suggesting some amino acid substitutions would be responsible for these functional modifications.

It is already well established in the literature that PnTx2-6 decreases sodium channel inactivation [78]. Although we have not assayed Tx2-6 isoforms from $P$. eickstedtae $(\mathrm{Pe}-\mathrm{V})$ and $P$. pertyi $(\mathrm{Pp}-\mathrm{V})$, we believe that them has similar effects on sodium channels like PnTx2-6 isoform and similar results would be expected, because these toxins are homologous. The species $P$. eickstedtae and $P$. pertyi are rarer spiders. In addition, since Tx1 is the most abundant toxin, only this molecule was used for electrophysiology assays. We believe that our data, as they are, already bring the news to arouse the curiosity of the scientific community in the area.

\section{Conclusion}

Our findings have shown that the protein composition and enzymatic activities of $\mathrm{Pe}-\mathrm{V}$ and $\mathrm{Pp}-\mathrm{V}$ are highly similar to those of Pn-V, with only subtle differences. Moreover, isoforms of toxins previously described in $P$. nigriventer venom were identified in $\mathrm{Pe}-\mathrm{V}$ and $\mathrm{Pp}-\mathrm{V}$ - i.e. isoforms of the toxin Tx1 (PnTx1, PpTx1 and PeTx1) and Tx2-6 PnTx2-6, PpTx2-6 and PeTx2-6), which share high amino acid sequence similarity. Tx1 isoforms were able to block the Nav1.6 channel, though 
the kinetics of blockage and recovery were different for each isoform. Variations in biological activities and in differences in the venom composition (presence of isoforms as reported in our study) are widely described. In conclusion, these variations are very important for venom diversity as they can enhance the arsenal of biomolecules, thus contributing to the search for animal venom-derived proteins that could be candidate molecules for biotechnological applications.

\section{Abbreviations}

ACN: acetonitrile; ACU: acquired colorimetric unit; AMBIC: ammonium bicarbonate; $\mathrm{CaCl}_{2}$ : calcium chloride; CHCA: a-cyano-4-hydroxycinnamic acid; CTAB: hexadecyltrimethylammonium bromide; DC: dimethylcasein; DHB: 2,5-dihydroxybenzoic acid; DMEM: Dulbecco's Modified Eagle Medium; DTT: dithiotreitol; EDTA: 2-[2-[bis(carboxymethyl)amino]ethyl-(carboxymethyl)amino] acetic acid; EGTA: ethylene glycol-bis-(b-amino-ethyl ether) $\mathrm{N}, \mathrm{N}, \mathrm{N}^{\prime}, \mathrm{N}^{\prime}$-tetra-acetic acid; ESI: electrospray ionization; GMP: guanosine monophosphate; HA: hyaluronic acid; HEPES: 4-(2-hydroxyethyl)-1-piperazineethanesulfonic acid; HPLC: high-pressure liquid chromatography; IAA: iodoacetamide; $\mathrm{KOH}$ : potassium hydroxide; LC: liquid chromatography;

MALDI-TOF: matrix associated laser desorption/ionizationtime of flight; $\mathrm{MgCl}_{2}$ : magnesium chloride; MS: mass spectrometry; $\mathrm{MW}$ : mass weight; $\mathrm{NaCl}$ : sodium chloride; $\mathrm{NaOH}$ : sodium hydroxide; Nav: type voltage-dependent sodium channel; NMDA N-methyl d-aspartate; NO: nitric oxide; Pe: Phoneutria eickstedtae; Pe-V: Phoneutria eickstedtae venom; Ph: Phoneutria; Pn: Phoneutria nigriventer; Pn-V: Phoneutria nigriventer venom; Pp: Phoneutria pertyi; $\mathrm{Pp}-\mathrm{V}$ : Phoneutria pertyi venom; RP: reverse-phase; SDS-PAGE: sodium dodecyl sulfate polyacrylamide gel electrophoresis; TEA-Cl: tetraethylammonium chloride; TFA: trifluoracetic acid; TNBS: 2,4,6-trinitrobenzenesulfonic acid; Tx: toxin; UHPLC: ultrahigh-pressure liquid chromatography.

\section{Acknowledgments}

Thanks are due to Maria Nelman Antunes Souza and Luana Varela from Ezequiel Dias Foundation for the technical support with spiders.

\section{Availability of data and materials}

Not applicable

\section{Funding}

This research was supported by FAPEMIG: Rede n²6/1234, CBB-APQ-01317-09; CBB APQ-01781-17; APQ-00395-18; INCTTox: 573790/2008-6 and CAPES Toxinologia 063/201023038006280/2011). The mentioned funding sources had no involvement in the design of this study, its execution, analyses, interpretation of the data, or decision to submit the results to publication.

\section{Competing interests}

The authors declare that they have no competing interests.

\section{Authors' contributions}

FFF, JMR, JLS, TGS, VJPG contributed to the preparation, critical and scientific analysis of the figures and manuscript. MHB, SGF, MNC conceived and designed the experiments. AM conducted electrophysiology experiments and analysis. FFF and JLS performed the biochemical experiments and analysis. JLS and TGS took part in drafting the article. FFF, SGF and MHB were responsible for interpretation of data, drafting of the article and revision of the manuscript. All authors read and approved the final manuscript.

\section{Ethics approval}

Not applicable

\section{Consent for publication}

Not applicable.

\section{References}

1. Monge-Fuentes V, Arenas C, Galante P, Gonçalves JC, Mortari MR, Schwartz EF. Arthropod toxins and their antinociceptive properties: From venoms to painkillers. Pharmacol Ther. 2018 Aug;188:176-85.

2. Catterall WA, Cestèle S, Yarov-Yarovoy V, Yu FH, Konoki K, Scheuer T. Voltage-gated ion channels and gating modifier toxins. Toxicon. 2007 Feb;49(2):124-41.

3. Chaves-Moreira D, Matsubara FH, Schemczssen-Graeff Z, De Bona E, Heidemann VR, Guerra-Duarte C, Gremski LH, Chávez-Olórtegui C, Senff-Ribeiro A, Chaim OM, Arni RK, Veiga SS. Brown Spider (Loxosceles) Venom Toxins as Potential Biotools for the Development of Novel Therapeutics. Toxins (Basel). 2019 Jun;11(6):355.

4. Saez NJ, Herzig V. Versatile spider venom peptides and their medical and agricultural applications. Toxicon. 2019 Feb;158:109-26.

5. Lian W, Lian H, Li Q, Hu A, Liu S. The venom of spider Haplopelma hainanum suppresses proliferation and induces apoptosis in hepatic cancer cells by caspase activation in vitro. J Ethnopharmacol. 2018 Oct 28;225:169-77.

6. Peigneur S, Tytgat J. Toxins in Drug Discovery and Pharmacology. Toxins (Basel). 2018 Mar;10(3):126.

7. Windley MJ, Herzig V, Dziemborowicz SA, Hardy MC, King GF, Nicholson GM. Spider-Venom Peptides as Bioinsecticides. Toxins (Basel). 2012 Mar;4(3):191-227.

8. Borges MH, Figueiredo SG, Leprevost F V., De Lima ME, Cordeiro M do N, Diniz MRV, Moresco J, Carvalho PC, Yates JR. Venomous extract protein profile of Brazilian tarantula Grammostola iheringi: Searching for potential biotechnological applications. J Proteomics. 2016 Mar 16;136:35-47.

9. Touchard A, Koh JMS, Aili SR, Dejean A, Nicholson GM, Orivel J, Escoubas $P$. The complexity and structural diversity of ant venom peptidomes is revealed by mass spectrometry profiling. Rapid Commun Mass Spectrom. 2015 Mar 15;29(5):385-96.

10. Muttenthaler M, King GF, Adams DJ, Alewood PF. Trends in peptide drug discovery. Nat Rev Drug Discov. 2021 Apr;20(4):309-25.

11. Escoubas P, Quinton L, Nicholson GM. Venomics: unravelling the complexity of animal venoms with mass spectrometry. J Mass Spectrom. 2008;43(3):279-95.

12. Skinner WS, Adams ME, Quistad GB, Kataoka H, Cesarin BJ, Enderlin $\mathrm{FE}$, Schooley DA. Purification and characterization of two classes of neurotoxins from the funnel web spider, Agelenopsis aperta. J Biol Chem. 1989 Feb 5;264(4):2150-5. 
13. Borges MH, Andrich F, Lemos PH, Soares TG, Menezes TN, Campos FV, Neves LX, Castro-Borges W, Figueiredo SG. Combined proteomic and functional analysis reveals rich sources of protein diversity in skin mucus and venom from the Scorpaena plumieri fish. J Proteomics. 2018 Sep 15;187:200-11.

14. de Lima ME, Figueiredo SG, Matavel A, Nunes KP, da Silva CN, De Marco Almeida F, Diniz MRV, Cordeiro MN, Stankiewicz M, Beirão PSL. Phoneutria nigriventer Venom and Toxins: A Review. Spider Venom. 2016 Feb 24:71-99.

15. Martins R, Bertani R. The non-Amazonian species of the Brazilian wandering spiders of the genus Phoneutria perty, 1833 (Araneae: Ctenidae), with the description of a new species. Zootaxa. 2007;1526(1526):1-36.

16. Gomez MV., Kalapothakis E, Guatimosim C, Prado MAM. Phoneutria nigriventer venom: $A$ cocktail of toxins that affect ion channels. Cell Mol Neurobiol. 2002 Dec;22(5-6):579-88.

17. Borges MH, Lima ME de, Stankiewicz M, Pelhate M, Cordeiro M, Beirao PS. Structural and functional diversity in the venom of spiders of the genus Phoneutria. Anim Toxins State Art. 2009:291-311.

18. Escoubas P. Molecular diversification in spider venoms: $A$ web of combinatorial peptide libraries. Mol Divers. 2006 Nov;10(4):545-54.

19. Li J, Li D, Zhang F, Wang H, Yu H, Liu Z. A comparative study of the molecular composition and electrophysiological activity of the venoms from two fishing spiders Dolomedes mizhoanus and Dolomedes sulfurous. Toxicon. 2014;83:35-42.

20. Herzig V, John Ward R, Ferreira dos Santos W. Intersexual variations in the venom of the Brazilian 'armed' spider Phoneutria nigriventer (Keyserling, 1891). Toxicon. 2002 Oct;40(10):1399-406.

21. Richardson M, Pimenta AMC, Bemquerer MP, Santoro MM, Beirao PSL, Lima ME, Figueiredo SG, Bloch Jr C, Vasconcelos EAR, Campos FAP, Gomes PC, Cordeiro MN. Comparison of the partial proteomes of the venoms of Brazilian spiders of the genus Phoneutria. Comp Biochem Physiol C Toxicol Pharmacol. 2006 Mar-Apr;142(2-3):173-87.

22. Rezende L, Cordeiro MN, Oliveira EB, Diniz CR. Isolation of neurotoxic peptides from the venom of the 'armed' spider Phoneutria nigriventer. Toxicon. 1991;29(10):1225-33.

23. Lima ME, Pimenta AMC, Martin-Eauclaire MF, Zingali RB, Rochat H. Animal toxins: state of the art - perspectives in health and biotechnology. J Venom Anim Toxins incl Trop Dis. 2009;15(3):585-6. https://doi.org/10.1590/ S1678-91992009000300021.

24. Nunes KP, Costa-Gonçalves A, Lanza LF, Cortes SF, Cordeiro MN, Richardson M, Pimenta AMC, Webb RC, Leite R, de Lima ME. T×2-6 toxin of the Phoneutria nigriventer spider potentiates rat erectile function. Toxicon. 2008 Jun 1;51(7):1197-206.

25. Suntravat M, Cromer WE, Marquez J, Galan JA, Zawieja DC, Davies P, Salazar E, Sánchez EE. The isolation and characterization of a new snake venom cysteine-rich secretory protein (svCRiSP) from the venom of the Southern Pacific rattlesnake and its effect on vascular permeability. Toxicon. 2019 Jul;165:22-30.

26. da Silva GH, Hyslop S, Alice da Cruz-Höfling M. Lonomia obliqua caterpillar venom increases permeability of the blood-brain barrier in rats. Toxicon. 2004 Nov;44(6):625-34.

27. Soares ES, Mendonça MCP, da Cruz-Höfling MA. Caveolae as a target for Phoneutria nigriventer spider venom. Neurotoxicology. 2016 May;54:111-8.

28. Rapôso C, Odorissi PAM, Savioli SF, Hell RCR, Simões GF, Ruela-deSousa RR, Oliveira ALRO, Cruz-Hofling MAC. Triggering of Protection Mechanism against Phoneutria nigriventer Spider Venom in the Brain. PLoS One. 2014 Sep 11;9:e107292.

29. Cordeiro M do N, Diniz CR, do Carmo Valentim A, von Eickstedt VRD, Gilroy J, Richardson M. The purification and amino acid sequences of four Tx2 neurotoxins from the venom of the Brazilian "armed" spider Phoneutria nigriventer (Keys). FEBS Lett. 1992 Sep 28;310(2):153-6.

30. Cordeiro $M$ do $N$, de Figueiredo SG, Valentim A do C, Diniz CR, von Eickstedt VRD, Gilroy J, Richardson M. Purification and amino acid sequences of six Tx3 type neurotoxins from the venom of the Brazilian 'armed' spider Phoneutria nigriventer (keys.). Toxicon. 1993 Jan;31(1):35-42.
31. Figueiredo SG, Garcia MEL-P, Valentim ADC, Cordeiro MN, Diniz CR, Richardson M. Purification and amino acid sequence of the insecticidal neurotoxin $\mathrm{T} \times 4(6-1)$ from the venom of the 'armed' spider Phoneutria nigriventer (keys). Toxicon. 1995 Jan;33(1):83-93.

32. Martin-Moutot N, Mansuelle P, Alcaraz G, Dos Santos RG, Cordeiro MN, De Lima ME, Seagar M, Van Renterghem C. Phoneutria nigriventer toxin 1: A novel, state-dependent inhibitor of neuronal sodium channels that interacts with $\mu$ conotoxin binding sites. Mol Pharmacol. 2006 Jun;69(6):1931-7.

33. Silva AO, Peigneur S, Diniz MR V, Tytgat J, Beirão PSL. Inhibitory effect of the recombinant Phoneutria nigriventer Tx1 toxin on voltage-gated sodium channels. Biochimie. 2012 Dec;94(12):2756-63.

34. Yonamine C., Troncone LR., Camillo MA. Blockade of neuronal nitric oxide synthase abolishes the toxic effects of Tx2-5, a lethal Phoneutria nigriventer spider toxin. Toxicon. 2004 Jun 20;44:169-72.

35. Nunes KP, Cordeiro MN, Richardson M, Borges MN, Diniz SOF, Cardoso VN, et al. Nitric Oxide-Induced Vasorelaxation in Response to PnTx2-6 Toxin from Phoneutria nigriventer Spider in Rat Cavernosal Tissue. J Sex Med. 2010 Dec;7(12):3879-88.

36. Nunes KP, Toque HA, Borges MH, Richardson M, Clinton Webb R, de Lima ME. Erectile Function Is Improved in Aged Rats by PnTx2-6, a Toxin from Phoneutria nigriventer Spider Venom. J Sex Med. 2012 Oct;9(10):2574-81.

37. Kushmerick C, Kalapothakis E, Beirão PSL, Penaforte CL, Prado VF, Cruz JS, Diniz CR, Cordeiro MN, Gomez MV, Romano-Silva MA, Prado MA. Phoneutria nigriventer toxin Tx3-1 blocks A-type K+ currents controlling $\mathrm{Ca} 2+$ oscillation frequency in GH3 cells. J Neurochem. 1999 Apr;72(4):1472-81.

38. Leão RM, Cruz JS, Diniz CR, Cordeiro MN, Beirão PS. Inhibition of neuronal high-voltage activated calcium channels by the $\omega$-Phoneutria nigriventer Tx3-3 peptide toxin. Neuropharmacology. 2000 Jul 24;39(10):1756-67.

39. Dos Santos RG, Van Renterghem C, Martin-Moutot N, Mansuelle P, Cordeiro MN, Diniz CR, et al. Phoneutria nigriventer $\omega$-Phonetoxin IIA Blocks the Cav2 Family of Calcium Channels and Interacts with $\omega$-Conotoxin-binding Sites. J Biol Chem. 2002 Apr 19;277(16):13856-62.

40. Miranda D., Romano-Silva M., Kalapothakis E, Diniz C., Cordeiro M., Moraes-Santos T, De Marco L, Prado MA, Gomez MV. Spider neurotoxins block the $\beta$ scorpion toxin-induced calcium uptake in rat brain cortical synaptosomes. Brain Res Bull. 2001 Mar 15;54(5):533-6.

41. Guatimosim C, Romano-Silva MA, Cruz JS, Beirão PSL, Kalapothakis E, Moraes-Santos T, Cordeiro MN, Diniz CR, Gomez MV, Prado MA. A toxin from the spider Phoneutria nigriventer that blocks calcium channels coupled to exocytosis. Br J Pharmacol. 1997 Oct;122(3):591-7.

42. Prado MAM, Guatimosim C, Gomez M V., Diniz CR, Cordeiro MN, Romano-Silva $M$. A novel tool for the investigation of glutamate release from rat cerebrocortical synaptosomes: the toxin Tx3-3 from the venom of the spider Phoneutria nigriventer. Biochem J. 1996 Feb 15;314(Pt 1):145-50.

43. Rita Pereira EM, Souza JM, Carobin NV, Silva JF, Santos DC, Silva Júnior CA, Binda NS, Borges MH, Nagem RAP, Kushmerick C, Ferreira J, Castro Jr C], Ribeiro FM, Gomez MV. Phoneutria toxin PnTx3-5 inhibits TRPV1 channel with antinociceptive action in an orofacial pain model. Neuropharmacology. 2020 Jan 1;162:107826

44. Oliveira SM, Silva CR, Trevisan G, Villarinho JG, Cordeiro MN, Richardson M, Borges MH, Castro Jr CJ, Gomez MV, Ferreira J. Antinociceptive effect of a novel armed spider peptide T×3-5 in pathological pain models in mice. Pflügers Arch. 2016 May;468(5):881-94.

45. Rigo FK, Rossato MF, Borges V, Silva JF da, Pereira EMR, Ávila RAM, Trevisan G, dos Santos DC, Diniz DM, Silva MAR, Castro Jr CJ, Cunha TM, Ferreira J, Gomez MV. Analgesic and side effects of intravenous recombinant Pha1ß. J Venom Anim Toxins incl Trop Dis. 2020;26. https:// doi.org/10.1590/1678-9199-JVATITD-2019-0070.

46. Da Silva JF, Castro-Junior CJ, Oliveira SM, Dalmolin GD, Silva CR, Vieira LB, Diniz DM, Cordeiro MN, Ferreira J, Souza AH, Gomez MV. Characterization of the antinociceptive effect of $\mathrm{PhT} \times 3-4$, a toxin from Phoneutria nigriventer, in models of thermal, chemical and incisional pain in mice. Toxicon. 2015 Dec 15;108:53-61. 
47. Dalmolin GD, Silva CR, Rigo FK, Gomes GM, do Nascimento Cordeiro M, Richardson M, Silva MAR, Prado MAM, Gomez MV, Ferreira J. Antinociceptive effect of Brazilian armed spider venom toxin T×3-3 in animal models of neuropathic pain. Pain. 2011 Oct;152(10):2224-32.

48. de Lima M, Stankiewicz M, Hamon A, de Figueiredo S, Cordeiro M, Diniz C, Martin-Eauclaire MF, Pelhate M. The toxin Tx4(6-1) from the spider Phoneutria nigriventer slows down $\mathrm{Na}+$ current inactivation in insect CNS via binding to receptor site 3. J Insect Physiol. 2002 Jan;48(1):53-61.

49. Peigneur S, de Lima ME, Tytgat J. Phoneutria nigriventer venom: A pharmacological treasure. Toxicon. 2018 Sep 1;151:96-110.

50. de Figueiredo SG, de Lima ME, Cordeiro MN, Diniz CR, Patten D, Halliwell RF, Gilroy J, Richardson M. Purification and amino acid sequence of a highly insecticidal toxin from the venom of the Brazilian spider Phoneutria nigriventer which inhibits NMDA-evoked currents in rat hippocampal neurones. Toxicon. 2001 Feb-Mar;39(2-3):309-17.

51. Emerich BL, Ferreira RCM, Cordeiro MN, Borges MH, Pimenta AMC, Figueiredo SG, Duarte IDG, de Lima ME. D-Ctenitoxin-Pn1a, a Peptide From Phoneutria nigriventer Spider Venom, Shows Antinociceptive Effect Involving Opioid and Cannabinoid Systems, in Rats. Toxins (Basel). 2016 Apr 12;8(4):1-13.

52. Oliveira CFB, Alves DP, Emerich BL, Figueiredo SG de, Cordeiro M do $\mathrm{N}$, Borges MH, Richardson M, Pimenta AMC, Duarte IDG, Lima ME. Antinociceptive effect of PnTx4(5-5), a peptide from Phoneutria nigriventer spider venom, in rat models and the involvement of glutamatergic system. J Venom Anim Toxins incl Trop Dis. 2019;25. https://doi.org/10.1590/16789199-JVATITD-2019-0022.

53. Diniz MRV, Paiva ALB, Guerra-Duarte C, Nishiyama MY, Mudadu MA, Oliveira U, Yates JR, Junqueira-de-Azevedo IL. An overview of Phoneutria nigriventer spider venom using combined transcriptomic and proteomic approaches. PLoS One. 2018;13(8):e0200628.

54. Paiva ALB, Mudadu MA, Pereira EHT, Marri CA, Guerra-Duarte C, Diniz MRV. Transcriptome analysis of the spider Phoneutria pertyi venom glands reveals novel venom components for the genus Phoneutria. Toxicon [Internet]. 2019 May;163:59-69.

55. Barrio A, Brazil OV. Ein neues Verfahren der Giftentnahme bei Spinnen. Experientia. 1950 Mar;6:112-3.

56. Smith PK, Krohn RI, Hermanson GT, Mallia AK, Gartner FH, Provenzano MD, Fujimoto EK, Goeke NM, Olson BJ, Klenk DC. Measurement of protein using bicinchoninic acid. Anal Biochem. 1985 Oct;150(1):76-85.

57. Heussen C, Dowdle EB. Electrophoretic analysis of plasminogen activators in polyacrylamide gels containing sodium dodecyl sulfate and copolymerized substrates. Anal Biochem. 1980 Feb;102(1):196-202.

58. Gouveia AICB, da Silveira RB, Nader HB, Dietrich CP, Gremski W, Veiga SS. Identification and partial characterisation of hyaluronidases in Lonomia obliqua venom. Toxicon. 2005 Mar 15;45(4):403-10.

59. Lin Y, Means GE, Feeney RE. The action of proteolytic enzymes on N,Ndimethyl proteins. Basis for a microassay for proteolytic enzymes. J Biol Chem. 1969 Feb 10;244(3):789-93.

60. Di Ferrante $\mathrm{N}$. Turbidimetric measurement of acid mucopolysaccharides and hyaluronidase activity. J Biol Chem. 1956 May;220(1):303-6.

61. Schägger $H$, von Jagow $G$. Tricine-sodium dodecyl sulfate-polyacrylamide gel electrophoresis for the separation of proteins in the range from 1 to 100 kDa. Anal Biochem. 1987 Nov 1;166(2):368-79.

62. Sanson AL, Cosenza-Contreras M, DeMarco R, Neves LX, Mattei B, Silva GG, Andrade PHV, Borges MHG, Castro W. The golden mussel proteome and its response to niclosamide: Uncovering rational targets for control or elimination. J Proteomics. 2020;217:103651.

63. Silva CN da, Dourado LFN, de Lima ME, da Silva Cunha A. Pnpp-19 peptide as a novel drug candidate for topical glaucoma therapy through nitric oxide release. TransI Vis Sci Technol. 2020 Jul;9(8):33.
64. Feitosa L, Gremski W, Veiga SS, Elias MCQ, Graner E, Mangili OC, Brentani RR. Detection and characterization of metalloproteinases with gelatinolytic, fibronectinolytic and fibrinogenolytic activities in Brown spider (Loxosceles intermedia) venom. Toxicon. 1998 Jul;36(7):1039-51.

65. Chaves-Moreira D, Matsubara FH, Schemczssen-Graeff Z, De Bona E, Heidemann VR, Guerra-Duarte C, Gremski LH, Chávez-Olórtegui C, Senff-Ribeiro A, Chaim OM, Arni RK, Veiga SS. Brown spider (Loxosceles) venom toxins as potential biotools for the development of novel therapeutics. Toxins (Basel). 2019 Jun;11(6):355.

66. Khan N, Niazi ZR, Rehman F ur, Akhtar A, Khan MM, Khan S, Baloch N, Khan S. Hyaluronidases: A Therapeutic Enzyme. Protein Pept Lett. 2018;25(7):663-76.

67. Laurent TC, Fraser JRE. Hyaluronan 1. FASEB J. 1992;6(7):2397-404.

68. Pimenta AMC, Rates B, Bloch C, Gomes PC, Santoro MM, de Lima ME, Richardson M, Cordeiro MN. Electrospray ionization quadrupole timeof-flight and matrix-assisted laser desorption/ionization tandem timeof-flight mass spectrometric analyses to solve micro-heterogeneity in post-translationally modified peptides from Phoneutria nigriventer (Aranea, Ctenidae) venom. Rapid Commun Mass Spectrom. 2005;19(1):31-7.

69. Escoubas P, Sollod B, King GF. Venom landscapes: Mining the complexity of spider venoms via a combined cDNA and mass spectrometric approach. Toxicon. 2006 Jun;47(6):650-63.

70. Duran LH, Rymer TL, Wilson DT. Variation in venom composition in the Australian funnel-web spiders Hadronyche valida. Toxicon X. 2020 Nov 28;8:100063.

71. Andrade-Silva D, Zelanis A, Travaglia-Cardoso SR, Nishiyama MY, Serrano SMT. Venom Profiling of the Insular Species Bothrops alcatraz: Characterization of Proteome, Glycoproteome, and N-Terminome Using Terminal Amine Isotopic Labeling of Substrates. J Proteome Res. 2021 Feb 5;20(2):1341-58.

72. Palagi A, Koh JMS, Leblanc M, Wilson D, Dutertre S, King GF, Nicholson GM, Escoubas P. Unravelling the complex venom landscapes of lethal Australian funnel-web spiders (Hexathelidae: Atracinae) using LC-MALDITOF mass spectrometry. J Proteomics. 2013 Mar 27;80:292-310.

73. Wilson D, Alewood PF. Taxonomy of Australian Funnel-web spiders using rp-HPLC/ESI-MS profiling techniques. Toxicon. 2006 May;47(6):614-27.

74. Binford G. Differences in venom composition between orb-weaving and wandering Hawaiian Tetragnatha (Araneae). Biol J Linn Soc. 2001 Jan 14;74(4):581-95.

75. Diniz CR, Cordeiro MN, Junor LR, Kelly P, Fischer S, Reimann F, Oliveira $E B$, Richardson $M$. The purification and amino acid sequence of the lethal neurotoxin Txl from the venom of the Brazilian 'armed' spider Phoneutria nigriventer. FEBS Lett. 1990 Apr 24;263(2):251-3.

76. Mattiello-Sverzut AC, Fontana MD, Diniz CR, da Cruz-Höfling MA. Pathological changes induced by $\mathrm{PhT} \times 1$ from Phoneutria nigriventer spider venom in mouse skeletal muscle in vitro. Toxicon. 1998 Oct;36(10):1349-61.

77. Diniz MRV, Theakston RDG, Crampton JM, Nascimento Cordeiro M do, Pimenta AMC, De Lima ME, Diniz CR. Functional expression and purification of recombinant $T \times 1$, a sodium channel blocker neurotoxin from the venom of the Brazilian "armed" spider, Phoneutria nigriventer. Protein Expr Purif. 2006 Nov;50(1):18-24.

78. Matavel A, Fleury C, Oliveira LC, Molina F, de Lima ME, Cruz JS, Cordeiro MN, Richardson M, Ramos CHI, Beirão PSL. Structure and Activity Analysis of Two Spider Toxins That Alter Sodium Channel Inactivation Kinetics. Biochemistry. 2009 Apr 14;48(14):3078-88.

79. Silva CN, Nunes KP, Torres FS, Cassoli JS, Santos DM, Almeida FDM, Matavel A, Cruz J, Santos-Miranda A, Nunes ADC, Castro CH, Ávila RAM, Chávez-Olórtegui C, Láuar SS, Felicori L, Resende JM, Camargos ERS, Borges MH, Cordeiro MN, Peigneur S, Tytgat J, Lima ME. PnPP-19, a Synthetic and Nontoxic Peptide Designed from a Phoneutria nigriventer Toxin, Potentiates Erectile Function via NO/cGMP. J Urol. 2015 Nov;194(5):1481-90. 